\title{
EFFICIENCY OF SILVER-COATED TITANIUM ALLOY SCREWS IN THE PREVENTION OF IMPLANT-ASSOCIATED INFECTIONS
}

\author{
(1) Nesrin Akkoyun Kayran' ${ }^{1}$, (1) Melih Üçer ${ }^{1}$, (1) Ali Ender Ofluoğlu² \\ ${ }^{1}$ University of Health Sciences Turkey, Kanuni Sultan Süleyman Training and Research Hospital, Clinic of Neurosurgery, İtanbul, Turkey \\ 2istanbul Bakırköy Prof. Dr. Mazhar Osman Mental Health and Nerve Diseases Research and Training Hospital, Clinic of Psychiatry, Neurology \\ and Neurosurgery, Istanbul, Turkey
}

Objective: Instrumentation is used for treating spinal fractures. Degenerative and neoplastic spine diseases have gradually increased in recent years because of advancements in spine surgery. The major disadvantage of instrumentation is implant-associated infections that result in morbidity and mortality, in addition to considerable financial losses because of increased treatment costs. This study examined the effectiveness of Ti alloy screws coated with Silver (Ag) ion nanoparticles in preventing infection in the rat spine.

Materials and Methods: In this study, 24 male, six-month-old white Sprague-Dawley rats were used. The animals were divided into three groups, each with an equal number of animals. A pedicle screw of appropriate size was placed in the lumbar vertebrae of animals and inoculated with a 1 million CFU/10 microliter Staphylococcus Aureus ATCC 29213 strain. A Ti alloy microscrew with a surface area of $25 \mathrm{~mm}^{2}$ was placed in the first group, Ag-coated Ti alloy microscrew with a surface area of $25 \mathrm{~mm}^{2}$ was placed in the second group, and a Ag-coated Ti alloy microscrew with a surface area of $50 \mathrm{~mm}^{2}$ was placed in the third group.

Results: Screw and tissue samples were taken and microbiologically examined. After microbiological evaluation, no statistically significant difference was reported between these groups in terms of the number of microorganisms growing on the screw and tissue.

Conclusion: Because of the difficulties and financial burdens that arise after the occurrence of an infection, the importance and necessity of developing anti-infective biomaterials are very clear. No anti-infective effect was observed in the Ag-coated pedicle screws in our study. Solutionfocused studies are required for developing implants with better biocompatibility, lower infection rates, and lower costs in the following years.

Keywords: Spinal infection, implant associated infections, surgical site infection, silver ions

\section{INTRODUCTION}

Beyond enabling daily basic functions of patients with the aim of a painless and disability-free life, in recent years, the aim has been to have patients recover to an extent that enables them to have a comfortable social life. Therefore, surgical techniques based on preserving the biodynamic properties of the spine are being developed. With new developments in spine surgery and advances in the instrumentation industry, the use of implants in surgical treatment has gradually increased. In addition to the remarkable advantages of implants in the treatment of spinal diseases, they have considerable disadvantages such as neural injury, host incompatibility with foreign body, technical failures in implant application, high postoperative infection rates, and increased treatment costs. Among these, one of the most common implant-associated complications is implantassociated infection ${ }^{(1,2)}$. The literature review shows that this rate varies between $1 \%$ and $8.5 \%$ in large case series ${ }^{(3-5)}$. These types of infections can cause considerable morbidity and even mortality ${ }^{(6)}$. The treatment of implant-associated infections requires intensive antibiotherapy and impairs patients' quality of life as a result of removal of the implant, long hospital-stay, and long periods of immobilization ${ }^{(7)}$. The use of prophylactic systemic antibiotics is insufficient in combating these types of infections $s^{(8)}$. The risk of serious toxicity arises because of the use of high doses in treatment with systemic antibiotics, and local administration involves technical difficulties ${ }^{(9)}$. Consequently, medical treatment is insufficient for such infections because there is a different mechanism originating from biomaterials in the development of implant-associated infections. Based on the available information, it was considered that shaping the implant surface in a manner that prevents bacterial adhesion may reduce implant-associated infection ${ }^{(10)}$. Based on this view, in our study, titanium alloy screws (Ti6Al4V), which are frequently used today in spinal surgery, and Ti alloy screws with a Silver (Ag)-coated surface of different sizes were compared by creating an experimental model in the rat spine to test their effect on bacteria. 


\section{MATERIALS AND METHODS}

The microscrews used Ti6A14V alloy microscrews with a surface area of $25 \mathrm{~mm}^{2}$ were used in the first group (Normed, Germany). Ti6A14V alloy microscrews with a surface area of 25 $\mathrm{mm}^{2}$, which were coated in $\mathrm{Ag}$ using the sol-gel method, were used in the second group (Tasarımmed, Turkey). In the third group, Ti6A14V alloy microscrews with a surface area of 50 $\mathrm{mm}^{2}$, which were coated in Ag using the sol-gel method, were used (Tasarımmed, Turkey). In this study, the Staphylococcus aureus ATCC 29213 strain, which was previously shown to cause osteomyelitis in the rat spine, was used.

\section{Preparation of Animals and Surgical Intervention}

This research was approved by Bakırköy Prof. Dr. Mazhar Osman Training and Research Hospital, Clinic of Psychiatry, Neurology and Neurosurgery Ethics Board (2012-47773). In this study, 24 male, white six-month-old Sprague Dawley rats weighing between 300 and $350 \mathrm{~g}$ were used. Each group was maintained in two separate cages. Moreover, each animal was observed in a separate cage on the first postoperative day. The animals were randomly numbered, and three different groups of eight were formed. The animals that were planned to undergo surgery were separated from the group one day before the operation, and their lumbar back region was shaved with the help of a depilatory cream (Figure 1). The instruments to be used in the surgery were sterilized in a steam autoclave (Amsco, USA) at $134{ }^{\circ} \mathrm{C}$ the night before. After being sedated with sevoflurane (Sevorane, Abbott, USA), the animals were taken in for surgery under general anesthesia induced with a $60 \mathrm{mg} / \mathrm{kg}$ intraperitoneal injection of ketamine hydrochloride (Ketalar ${ }^{\circledR}$, Pfizer, USA). The animals were secured to the operating table in prone position (Figure 1).

At the start of the surgery, the incision area was cleaned with povidone-iodine and covered with sterile fabric. A vertical skinsubcutaneous incision of $1.5-2 \mathrm{~cm}$ length was made in the lumbar region (approximately the L3-4 region) with a no. 11 scalpel (Figure 2A).

The fascia was seen and opened in a vertical plane with a new no. 11 scalpel parallel to the skin incision (Figure 2A). The paravertebral muscles were stripped from the unilateral spinous

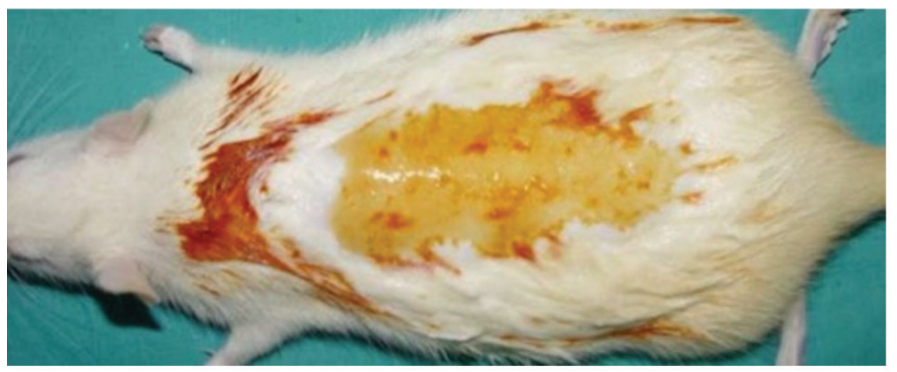

Figure 1. The thoracolumbar region of the animal was shaved and cleaned with povidone-iodine, and it was placed on the operating table in prone position. process and laminae. The lamina and facet joints were seen (Figure 2B). The surface of lamina was decorticated with a no. 11 scalpel. A screw insertion slot was opened with a 20-gauge needle in a lateral direction to the junction point of the lamina and facet joint (Figure 3A). In the slot on the lamina, $\mathrm{Ti}$ alloy microscrews with a surface area of $25 \mathrm{~mm}^{2}$ was inserted in the first group; Ti alloy microscrews with a surface area of $25 \mathrm{~mm}^{2}$ that are coated with 5 to $8 \mathrm{mcm}$-thick silver layer were inserted in the second group; and $\mathrm{Ti}$ alloy microscrews with a surface area of $50 \mathrm{~mm}^{2}$ that are coated with 5 to $8 \mathrm{mcm}$-thick silver layer were inserted in the third group; and the inserted screws were tightened with a screwdriver (Figure 3B). For consistent growth of both soft tissue and implant infection, inoculation with 105 CFU was required ${ }^{(11)}$. Bacterial solutions in a volume of $10 \mu \mathrm{l}$ were applied onto the screw in the surgical field using a $50 \mu \mathrm{l}$ micropipette in all groups, and the fascia was closed. Note that follow-up was performed for 21 days. During the follow-up period, the animals were closely followed up to monitor their feeding, behaviors and wounds (redness and discharge), and the changes were noted on a daily basis.

The incision sites of animals had the same characteristics for all groups. In $90 \%$ of all groups, skin rash and swelling were present at the wound site; however, there was no discharge in any of the animals. When the swelling was palpated, it was hard to touch and fixed under the skin (Figure 4A, B).

There were no neurological complications developed in any of the animals. Two animals died in the preoperative period because of respiratory failure caused by anesthesia, and one
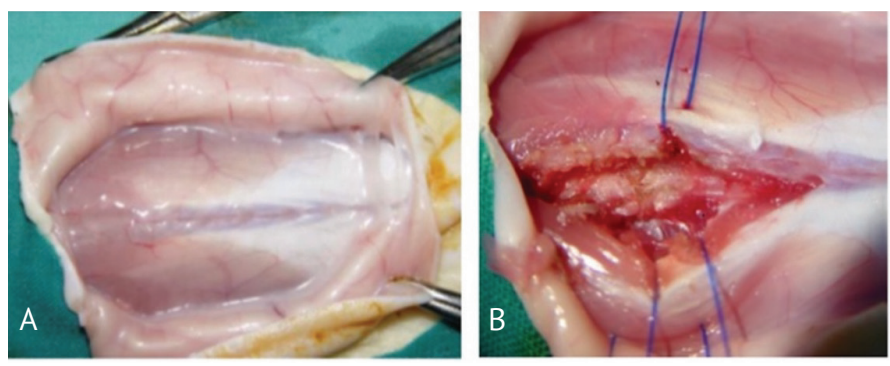

Figure 2. A) Paravertebral muscles of the thoracolumbar region and the lumbar fascia are seen following the skin incision (left image), B) Paravertebral muscles are stripped away, and the lamina and facet joints are exposed (right image).

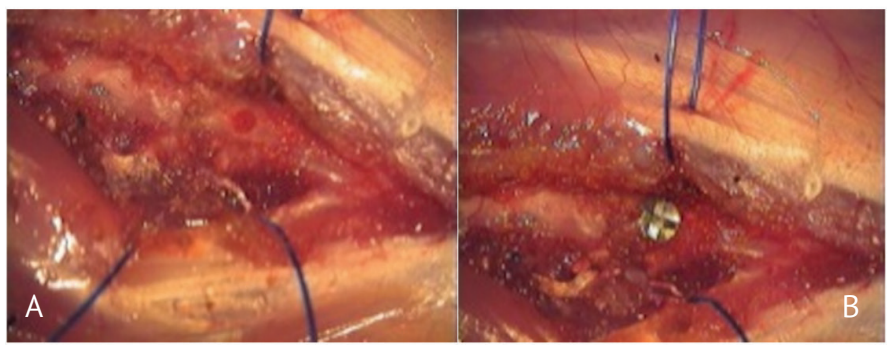

Figure 3. A) The screw entry slot that has been opened can be seen in the image on the left, B) The screw has been placed through the slot that was opened, as seen in the image on the right. 
turkishspine

animal died in the early postoperative period because of respiratory failure caused by anesthesia. The animals that died were replaced with new animals.

\section{Statistical Analysis}

The NCSS (Number Cruncher Statistical System) 2015 and PASS (Power Analysis and Sample Size) 2015 Statistical Software (Utah, USA) were used for statistical analysis when evaluating the results obtained from the study. The study data were assessed using descriptive statistical methods (mean and standard deviation). Moreover, for comparing quantitative data, the Kruskal-Wallis test was used for inter-group comparison of parameters that did not show a normal distribution, and the Mann-Whitney $U$ test was used to determine the group causing the difference. The Spearman's correlation analysis was used to evaluate the relations between parameters. $P$ values of $<0.05$ were considered to be statistically significant.

\section{RESULTS}

\section{Method and Follow-up Duration}

Three animals died on the postoperative day zero because of anesthesia-associated complication. All three animals were replaced with new animals on the same day. No other animal died during the 21-day follow-up period. The body weight and body temperature of the animals were measured on days 0,3 ,

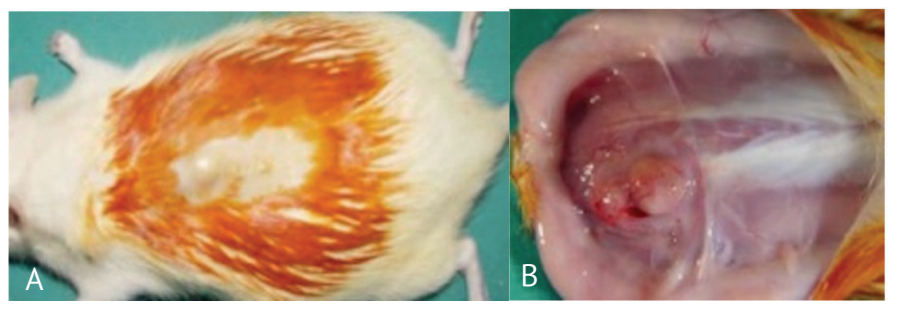

Figure 4. A) The stage of obtaining a sample from an animal in the first group after sacrification. The incision and abscess formation under the skin in the incision area is seen in the image. B) The skin-subcutaneous tissue has been cut through and the fascia and paravertebral muscles are exposed, as seen in the image. There is an abscess formation extending from the paravertebral muscles to the subcutaneous area in the surgical site.
7,15 and 21. No changes were detected in the body weight and body temperature in any of the animals.

\section{Evaluation of Infection}

Bone-related infection developed in all groups that were inoculated with bacteria. Bacterial growth occurred in all of the screws and bone samples. All animals had swelling that was palpable on the skin. When an incision was made on this swelling, purulent effusion was observed in three animals in the first group, four animals in the second group, and three animals in the third group. A stiffer and more organized tissue was encountered in other animals. The number of microorganisms that grew on the screw and in the tissue was then statistically compared (Table 1).

\section{Microbiological Evaluation}

Bone samples taken from each animal under aseptic conditions were placed in sterile falcon tubes. The bones were then weighed in a precision balance (Shimadzu, Libror AEG-120, Japan) and mechanically homogenized in $10 \mathrm{~mL}$ of serum in a sterile mortar. After homogenization, the samples were spread on tryptic soy agar after serial dilution. After $24 \mathrm{~h}$ of incubation at $37{ }^{\circ} \mathrm{C}$, the bacterial count was quantitatively determined (CFU/g). The presence of growth on screws was investigated by placing the screws in $0.5 \mathrm{~mL}$ of TSB and vortexing it and then inoculating that onto TSA growth medium. No bacteria other than Staphylococcus aureus was detected in the inoculated media (Table 2).

Comparison of groups revealed no statistically significant difference between the number of microorganisms on the screw $(p=0.968>0.05)$. Paired comparisons between these groups did not reveal any statistically significant difference in terms of the number of microorganisms on the screw $(p>0.05)$. Comparison of the number of microorganisms per gram in tissue revealed no statistically significant difference between the groups ( $p=0.403>0.05$ ). Paired comparisons did not reveal any statistically significant difference between these groups in terms of the number of microorganisms per gram in tissue $(p>0.05)$.

Table 1. Number of microorganisms that grew on the screws

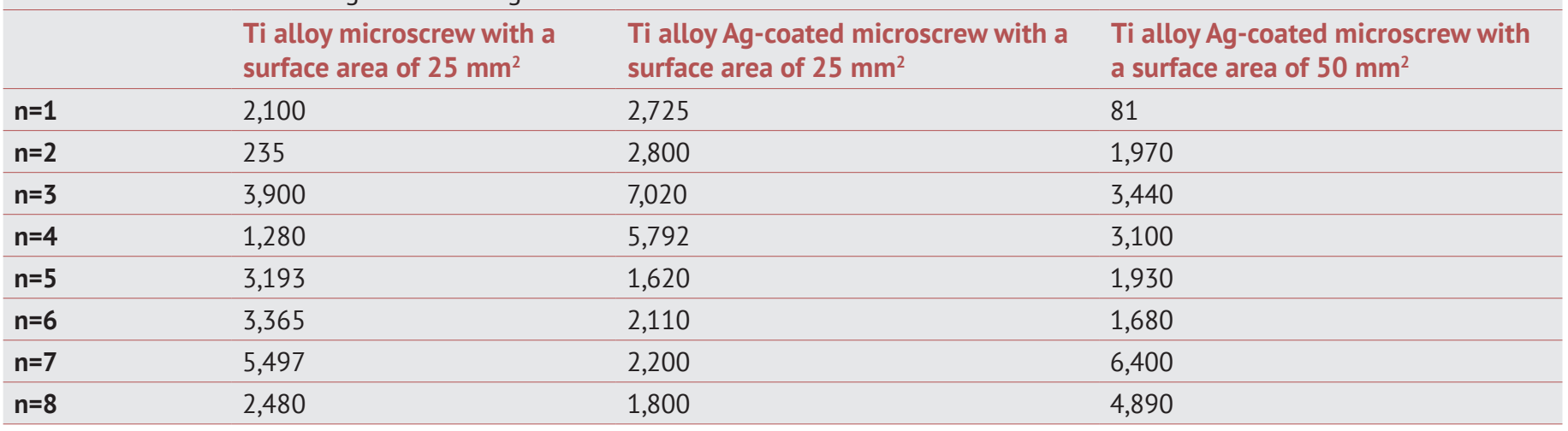


Table 2. Number of microorganisms per gram in bone tissue

\begin{tabular}{|c|c|c|c|}
\hline & $\begin{array}{l}\text { The group in which a Ti alloy } \\
\text { microscrew with a surface area of } \\
25 \mathrm{~mm}^{2} \text { was placed }\end{array}$ & $\begin{array}{l}\text { The group in which a Ti alloy Ag- } \\
\text { coated microscrew with a surface } \\
\text { area of } 25 \mathrm{~mm}^{2} \text { was placed }\end{array}$ & $\begin{array}{l}\text { The group in which a Ti alloy Ag-coated } \\
\text { microscrew with a surface area of } 50 \\
\mathrm{~mm}^{2} \text { was placed }\end{array}$ \\
\hline$n=1$ & 66,877 & 53,611 & 184,872 \\
\hline$n=2$ & 6,486 & $1,713,910$ & 139,024 \\
\hline$n=3$ & 121,132 & 414,787 & 331,250 \\
\hline$n=4$ & 175,291 & 278,422 & 223,502 \\
\hline$n=5$ & 322,656 & 243,983 & 98,918 \\
\hline$n=6$ & 171,755 & 279,117 & 770,718 \\
\hline$n=7$ & 287,577 & 183,457 & 333,512 \\
\hline$n=8$ & 250,555 & 315,080 & 304,550 \\
\hline
\end{tabular}

\section{DISCUSSION}

In the last two decades, rapid advances have been made in general medicine, as well as in the field of spine surgery in terms of diagnosing and treating diseases. Because of the developments in biomaterial technology and nanotechnology, considerable changes have been achieved in the implants used in spine surgery. These developments significantly increased the number of surgeries using biomaterials, and consequently brought about biomaterial-associated problems. In particular, in spine instrumentation, there are many complications arising from the most frequently used metal alloy screws. Among these complications, implant-associated infections are most common. While the infection rate is $\sim 1 \%$ in the interventions where metal implants are not used in spinal surgery, this rate varies between $1 \%$ and $8.5 \%$ in cases where metal implants are used $(3-5,12,13)$. Implants act as passive surfaces prone to bacterial adhesion and biofilm formation. A recent study reported an infection rate as high as $21 \%$ after complex adult spine deformity surgery where the operation duration was long ${ }^{(14)}$. Antibiotherapy alone is insufficient in the presence of implants infection, and revision surgery is inevitable in patients who do not respond to medical treatment and especially in late-onset infection ${ }^{(15)}$. In addition to the medical and social problems caused by all these situations, the financial burden that arises is a serious problem $^{(16)}$.

Staphylococcus epidermidis and S. aureus are most commonly isolated in biomaterial-associated infections ${ }^{(17,18)}$. Although less frequently, other microorganisms that are isolated include $E$. coli, Peptococcus, Pseudomonas aeruginosa, Proteus mirabilis and group $A$ beta hemolytic streptococci(19). The major pathogenic cause of biometal, bone, joint and soft tissue infections is $S$. aureus $^{(20)}$. Therefore, in this study, a S. aureus ATCC 29213 strain, which is known to lead to the development of osteomyelitis, was used.

In recent years, Ti alloy metal implants have frequently been preferred in surgical instrumentation. Greater bone adhesion and a more stable structure is achieved with Ti implants compared to other metals. Their better adhesion to bone and stable structure have made $\mathrm{Ti}$ implants become more preferable(21). Placement of implants into tissue causes certain changes in the natural response that normally occurs in a damaged tissue ${ }^{(22)}$. Therefore, the implant surface provides a suitable surface for bacteria to settle and colonize and paves the way for infection by disrupting the host defence mechanisms.

It was thought that coating the surface of biomaterials with antibacterial agents to prevent them from constituting a ground for bacterial settlement and biofilm formation could be a solution, and many materials were used for this purpose. One of these materials is $\mathrm{Ag}$, which has been known since ancient times to have an anti-infective effect and is used in many areas today for its anti-infective characteristic. The first written document on the antiseptic effect of $\mathrm{Ag}$ is the book of King Menes of Egypt that dates back to around 3600 B.C.(23). Ag is a noble metal that lies in Group $1 B$ with the atomic number 47 in the periodic table ${ }^{(24)}$. It has the highest electrical and thermal conductivity compared to other metals and is resistant to corrosion. It is known that both its free form and Ag salts have an antimicrobial effect ${ }^{(25)}$. However, many studies have shown that Ag exhibits its antiseptic effect best in its oxidative state, which is the +1 ion form ${ }^{(26)}$. Moreover, the dimensions of nanoparticles are of great importance in antibacterial efficacy. As the particle size gets smaller, the antibacterial efficacy increases. Several studies have shown that $\mathrm{Ag}$ nanoparticles have antimicrobial efficacy ${ }^{(27-30)}$. Ag exhibits antibacterial activity through its oligodynamic properties. Ag ions coming out of metallic Ag with the oligodynamic effect are adsorbed by bacterial cells and this leads to a toxic effect and activates its antibacterial efficacy ${ }^{(31)}$. Ag ions liberated from metallic Ag are positively charged. The electronegative surface of bacteria attracts positively charged $\mathrm{Ag}$ ions. Positively charged $\mathrm{Ag}$ ions have an affinity to negatively charged sulfhydryl groups in the enzyme system of the cell wall. By binding these groups, they prevent the transmembranous energy transfer and electron transport of bacteria. Moreover, they inhibit the formation of a protective film ${ }^{(32)}$.

In the literature, $\mathrm{Ag}$ compounds and salts in various forms and different chemical structures such as impregnation and coating 
are used with many different medical products. Silver nitrate and silver sulfadiazine are among the ones that are used most frequently ${ }^{(33,34)}$. Antimicrobial activity is related to the method in which $\mathrm{Ag}$ is used and the number of ions released as a result $t^{(35)}$. Most in vitro tests performed have yielded positive results ${ }^{(36,37)}$. In vivo studies, however, have revealed that the results can take a very different shape within the organism. Clinical studies have been conducted, especially with arterial grafts, central venous catheters, urinary catheters and ventricular drainage catheters. $\mathrm{Ag}$ has been used for antibacterial efficacy not only in medical interventional applications but also in many other fields. It has been used in fabrics because it can prevent nosocomial infections and its bactericidal effects have been demonstrated as a result ${ }^{(38)}$. Moreover, its antiseptic effects have been shown in environmental cleaning and cleaning of dishwater ${ }^{(39)}$.

In the study where Secinti et al. ${ }^{(40)}$ used Ag-coated metal alloy implants, it is reported that these implants had antibacterial efficacy. Direct electrical current was applied to the implants in the same study; it was shown that the ion release and antibacterial effect increased significantly. It was reported that uncoated metal alloy screws to which direct current was applied had significant antibacterial efficacy compared to the ones to which current was not applied ${ }^{(40)}$. The long-term protective effects of $\mathrm{Ti}$ implants coated with $\mathrm{Ag}$ ion-doped ceramic nanopowder against antibacterial activity have been shown in an in vivo experimental study by Kose et al.(41). In a clinical study by Riley et al. ${ }^{(42)}$ that included 1309 patients, it was found that silver oxide-coated urinary catheters increased bacteriuria. Silver acetate-coated arterial grafts were prophylactically used in 430 patients in the study by Larena-Avellaneda et al. ${ }^{(43)}$, and no difference was observed compared with the control group. In the experimental study by Schneider et al. ${ }^{(44)}$ where they performed vascular grafts, no difference was observed between silver-coated and rifampin-impregnated grafts. In the study by Camargo et al.(45) where they performed on 109 patients hospitalized in the intensive care unit, no significant difference was reported in Ag-coated central venous catheters in terms of infection compared with the control group. When applied locally and topically on the body surface, many different forms of $\mathrm{Ag}$ such as silver sulfadiazine, silver hydroalginate, silvercoated silicon and silver nitrate have been shown to have antibacterial efficacy at various levels in clinical studies with large case series and meta-analyses ${ }^{(46-49)}$.

There are two handicaps to using $\mathrm{Ag}$ in implants. The first handicap is that the presence of ions is temporary depending on the amount of material. The other handicap is the risk of toxicity. It has been stated in the literature that no toxic effects were observed in the amounts used in many experimental and clinical studies ${ }^{(50)}$. However, different results were obtained in the clinical study by Massè et al. ${ }^{(51)}$ in which they placed $50 \mathrm{Ag}$ coated stainless steel screws and 56 uncoated stainless steel screws in the lower extremities of 106 patients. Although there was no statistically significant difference between the screws in terms of culture positivity, the study was terminated because of a significant increase in the serum $\mathrm{Ag}$ levels ${ }^{(51)}$. In vivo study by Hazer et al. ${ }^{(52)} \mathrm{Ag}$ nanoparticle coated Ti screws were shown to have antimicrobial effect. However, in our study comparing $\mathrm{Ag}$ coated $\mathrm{Ti}$ screws with $\mathrm{Ti}$ screws, there was no significant difference between the groups $^{(52)}$. The silver +1 nanoparticle count is the primary factor that provides antibacterial efficacy; however, the implant surface area is the main factor that affects the number of ions that are released. Therefore, Ag-coated microscrews with two different surface areas, one with a 25 $\mathrm{mm}^{2}$ and the other with a $50 \mathrm{~mm}^{2}$ surface area, were used in our study. However, no difference was reported between these two microscrews, and antibacterial efficacy could not be demonstrated. It is understood that although the release of nanoparticles from Ag-coated implant surfaces does mostly provide antibacterial efficacy in in vitro tests performed with proper solutions; this effect is not at the desired level in the body where there is an environment that is dense with electrolytes. It is thought that this may be related to the fact that the oxidation of silver and the release of nanoparticles in the body does not occur in the same way as it does under in vitro conditions. Furthermore, the nanoparticle release takes place in a limited time in relation to the amount of coating that is present.

\section{CONCLUSION}

Today, implant-related infections remain as a serious problem and the financial losses in addition to medical and social losses that occur as a result cannot be underestimated. It is of great importance to develop biomaterials that can prevent infection. Ag-coated Ti alloy microscrews with two different surface areas and uncoated standard $\mathrm{Ti}$ alloy microscrews were used in our study. When compared with the other group that was implanted uncoated titanium alloy screws, the two groups that were implanted with Ag-coated screws revealed no statistically significant difference, and no anti-infection effect was observed. Considering the difficulties and financial burdens that arise after the occurrence of an infection, the importance and necessity of developing anti-infective biomaterials are very clear today. Solution-focused further studies are required for developing implants with better biocompatibility, lower infection rates and lower costs in the following years.

\section{Ethics}

Ethics Committee Approval: This research was approved by Bakırköy Prof. Dr. Mazhar Osman Training and Research Hospital, Clinic of Psychiatry, Neurology and Neurosurgery Ethics Board (2012-47773).

Informed Consent: Experimental study.

Peer-review: Internally peer-reviewed.

\section{Authorship Contributions}

Surgical and Medical Practices: N.A.K., Concept: N.A.K., A.E.O., Design: N.A.K., A.E.O., Data Collection or Processing: M.Ü., 
Analysis or Interpretation: M.Ü., Literature Search: N.A.K., Writing: N.A.K.

Financial Disclosure: The authors declared that this study received no financial support.

Conflict of Interest: The authors have no conflicts of interest to declare.

\section{REFERENCES}

1. Hedequist D, Haugen A, Hresko T, Emans J. Failure of attempted implant retention in spinal deformity delayed surgical site infections. Spine. 2009;34:60-4.

2. Popat KC, Eltgroth M, Latempa T], Grimes CA, Desai TA. Decreased Staphylococcus epidermis adhesion and increased osteoblast functionality on antibiotic-loaded titania nanotubes. Biomaterials. 2007;28:4880-8.

3. Collins I, Wilson-MacDonald J, Chami G, Burgoyne W, Vinayakam $P$, Berendt $T$, et al. The diagnosis and management of infection following instrumented spinal fusion. Eur Spine J. 2008;1 7:445-50.

4. Liu D, Shen YX, Hao J. Analysis of complications associated with internal fixation for lumbar spondylolisthesis. Zhongguo Gu Shang. 2008;21:253-5

5. Weinstein MA, McCabe JP, Cammisa FP Jr. Postoperative spinal wound infection: a review of 2,391 consecutive index procedures. J Spinal Disord. 2000;13:422-6.

6. Habash M, Reid G. Microbial biofilms: their development and significance for medical device-related infections. J Clin Pharmacol. 1999;39:887-98.

7. Dunne WM Jr. Bacterial adhesion: seen any good biofilms lately? Clin Microbiol Rev. 2002;15:155-66.

8. Lucke M, Schmidmaier G, Sadoni S, Wildemann B, Schiller R, Haas NP, et al. Gentamicin coating of metallic implants reduces implantrelated osteomyelitis in rats. Bone. 2003;32:521-31.

9. Stewart PS. Mechanisms of antibiotic resistance in bacterial biofilms. Int J Med Microbiol. 2002;292:107-13.

10. Laratta JL, Shillingford JN, Hardy N, Lehman RA, Lenke LG, Riew KD. A dose-response curve for a gram-negative spinal implant infection model in rabbits. Spine (Phila Pa 1976). 2017;42:E1225-30. doi: 10.1097/BRS.0000000000002205.

11. Heidenau F, Mittelmeier W, Detsch R, Haenle M, Stenzel F, Ziegler $\mathrm{G}$, et al. A novel antibacterial titania coating: metal ion toxicity and in vitro surface colonization. Mater Sci Mater Med. 2005;16:883-8.

12. Picada R, Winter RB, Lonstein JE, Denis F, Pinto MR, Smith MD,et al. Postoperative deep wound infection in adults after posterior lumbosacral spine fusion with instrumentation: incidence and management. Spinal Disord. 2000;13:42-5.

13. Sapkas GS, Themistocleous GS, Mavrogenis AF, Benetos IS, Metaxas $\mathrm{N}$, Papagelopoulos PJ. Stabilization of the lumbar spine using the dynamic neutralization system. Orthopedics. 2007;30:859-65.

14. Soroceanu A, Burton DC, Oren JH, Smith JS, Hostin R, Shaffrey $\mathrm{Cl}_{\text {, }}$ et al. Medical complications after adult spinal deformity surgery: incidence, risk factors, and clinical impact. Spine (Phila Pa 1976). 2016;41:1718-23.

15. Kowalski TJ, Berbari EF, Huddleston PM, Steckelberg JM, Mandrekar JN, Osmon DR. The management and outcome of spinal implant infections: contemporary retrospective cohort study. Clin Infect Dis. 2007;44:913-20.

16. Abbey DM, Turner DM, Warson JS, Wirt TC, Scalley RD. Treatment of postoperative wound infections following spinal fusion with instrumentation. J Spinal Disord. 1995;8:278-83.

17. Hegde V, Park HY, Dworsky E, Zoller SD, Xi W, Johansen DO, et al. The use of a novel antimicrobial implant coating in vivo to prevent spinal implant infection. Spine (Phila Pa 1976). 2020;45:E305-11.
18. Gordon O, Miller RJ, Thompson JM, Ordonez AA, Klunk MH, Dikeman DA, et al. Rabbit model of Staphylococcus aureus implant-associated spinal infection. Dis Models Mech. 2020;13 13:dmm045385. doi: 10.1242/dmm.045385.

19. Gristina AG, Hobgood CD, Barth E. Biomaterial specificity, molecular mechanisms and clinical relevance of $S$. epidermidis and $S$. aureus infections in surgery. In: Pulverer G, Quie PG, Peters G (Eds.). Pathogenesis and clinical significance of coagulase-negative staphylococci. Fischer Verlag, Stuttgart 1987;pp:143-57.

20. Christensen GD, Simpson WA, Beachey EH. Bacterial adhesion: mechanisms and physiological signifiance. In: Savage DC, Fletcher MM (Eds.). Plenum, Newyork 1985; pp.279-305.

21. Soultanis K, Pyrovolou N, Karamitros A, Konstantinou V, Liveris J, Soucacos PN. Instrumentation loosening and material of implants as predisposal factors for late postoperative infections in operated idiopathic scoliosis. Stud Health Technol Inform. 2006;123:559-64.

22. Colnot C, Romero DM, Huang S, J Rahman, Currey JA, Nanci A, et al. Molecular analysis of healing at a bone-implant interface. J Dent Res. 2007;86:862-7.

23. Russell AD.; Hugo WB. 7 antimicrobial activity and action of silver. Prog Med Chem, 1994;31:351-70.

24. PubChem [Internet]. Bethesda (MD): National Library of Medicine (US), National Center for Biotechnology Information; 2004PubChem Element Summary for AtomicNumber 47, Silver; [cited 2021 Apr. 8]. Available from: https://pubchem.ncbi.nlm.nih.gov/ element/Silver

25. Kırk-Othmer. Encyclopedia of chemical technology. Fifth Edition. John Wiley \& Sons, New Jersey 1983;pp:1-14.

26. Valappil SP, Pickup DM, Carroll DL, Hope CK, Pratten J, Newport $\mathrm{RJ}$, et al. Effect of silver content on the structure and antibacterial activity of silver-doped phosphate-based glasses. Antimicrob Agents Chemother. 2007; 51:4453-61.

27. Markowska K, Grudniak AM, Wolska KI. Silver nanoparticles as an alternative strategy against bacterial biofilms. Acta Biochim Pol. 2013;60:523-30.

28. Rai M, Kon K, Ingle A, Duran N, Galdiero S, Galdiero M. Broadspectrum bioactivities of silver nanoparticles: the emerging trends and future prospects. Appl Microbiol Biotechnol. 2014;98:1951-61.

29. Hazer DB, Mut M, Dincer N, Saribas Z, Hazer B, Ozgen T. The efficacy of silver-embedded polypropylene-grafted polyethylene glycolcoated ventricular catheters on prevention of shunt catheter infection in rats. Childs Nerv Syst. 2012;28:839-46.

30. Nair LS, Laurencin CT. Nanofibers and nanoparticles for orthopaedic surgery applications. J Bone Joint Surg Am. 2008;90:128-31.

31. Galiano K, Pleifer C, Engelhardt K, Brössner G, Lackner P, Huck C, et al. Silver segregation and bacterial growth of intraventricular catheters impregnated with silver nanoparticles in cerebrospinal fluid drainages. Neurol Res. 2008;30:285-7.

32. Guggenbichler JP, Böswald M, Lugauer S, Krall T. A new technology of microdispersed silver in polyurethane induces antimicrobial activity in central venous catheters. Infection. 1999;27(Suppl 1):16-23.

33. Bosetti $M$, Massè $A$, Tobin $E$, Cannas $M$. Silver coated materials for external fixation devices: in vitro biocompatibility and genotoxicity. Biomaterials. 2002;23:887-92.

34. Neely AN, Gardner J, Durkee P, Warden GD, Greenhalgh DG, Gallagher JJ, et al. Are topical antimicrobials effective against bacteria that are highly resistant to systemic antibiotics? J Burn Care Res. 2009;30:19-29.

35. Furno F, Morley KS, Wong B, Sharp BL, Arnold PL, Howdle SM, et al. Silver nanoparticles and polymeric medical devices: a new approach to prevention of infection? J Antimicrob Chemother. 2004;54:1019-24.

36. Ma Y, Zhou T, Zhao C. Preparation of chitosan-nylon-6 blended membranes containing silver ions as antibacterial materials. Carbohydr Res. 2008;343:230-7. 
turkishspine

37. MacKeen PC, Person S, Warner SC, Snipes W, Stevens SE Jr. Silvercoated nylon fiber as an antibacterial agent. Antimicrob Agents Chemother. 1987;31:93-9.

38. O'Hanlon SJ, Enright MC. A novel bactericidal fabric coating with potent in vitro activity against meticillin-resistant Staphylococcus aureus (MRSA). Int J Antimicrob Agents. 2009;33:427-31.

39. Jeppsson $M$, Wernersson ES, Håkanson $H$. The effect of silver ions and chlorine on the survival of Staphylococcus aureus and Bacillus cereus in dishwater. Environ Technol. 2007;28:1419-27.

40. Secinti KD, Ayten M, Kahilogullari G, Kaygusuz G, Ugur HC, Attar A. Antibacterial effects of electrically activated vertebral implants. J Clin Neurosci. 2008;15:434-9.

41. Kose N, Otuzbir A, Peksen C, Kiremitçi A, Doğan A. A silver iondoped calcium phosphate-based ceramic nanopowder-coated prosthesis increased infection resistance. Clin Orthop Relat Res. 2013;471:2532-9.

42. Riley DK, Classen DC, Stevens LE, Burke JP. A large randomized clinical trial of a silver-impregnated urinary catheter: lack of efficacy and staphylococcal superinfection. Am J Med. 1995;98:349-56.

43. Larena-Avellaneda A, Russmann S, Fein M, Debus ES. Prophylactic use of the silver-acetate-coated graft in arterial occlusive disease: a retrospective, comparative study. J Vasc Surg. 2009;50:790-8.

44. Schneider F, O'Connor S, Becquemin JP. Efficacy of collagen silvercoated polyester and rifampin-soaked vascular grafts to resist infection from MRSA and Escherichia coli in a dog model. Ann Vasc Surg. 2008;22:815-21.

45. Camargo LF, Marra AR, Büchele GL, Sogayar AMC, Cal RGR, de Sousa JMA, et al. Double-lumen central venous catheters impregnated with chlorhexidine and silver sulfadiazine to prevent catheter colonisation in the intensive care unit setting: a prospective randomised study. J Hosp Infect. 2009;72:227-33.

46. Ahuja RB, Gupta A, Gur R. A prospective double-blinded comparative analysis of framycetin and silver sulphadiazine as topical agents for burns: a pilot study. Burns. 2009;35:672-6.

47. Collier M. Silver dressings: more evidence is needed to support their widespread clinical use. J Wound Care. 2009;18:77-8.

48. Kammerlander G, Afarideh R, Baumgartner A, Berger M, Fischelmayer $\mathrm{K}$, Hirschberger $\mathrm{G}$, et al. Clinical experiences of using a silver hydroalginate dressing in Austria, Switzerland and Germany. J Wound Care. 2008;17:384-8.

49. Spacciapoli P, Buxton D, Rothstein D, Friden P. Antimicrobial activity of silver nitrate against periodontal pathogens. J Periodontal Res. 2001;36:108-13.

50. Izci Y, Secer H, Akay C, Gonul E. Initial experience with silverimpregnated polyurethane ventricular catheter for shunting of cerebrospinal fluid in patients with infected hydrocephalus. Neurol Res. 2009;31:234-7.

51. Massè $A$, Bruno A, Bosetti $M$, Biasibetti $A$, Cannas $M$, Gallinaro P. Prevention of pin track infection in external fixation with silver coated pins: clinical and microbiological results. J Biomed Mater Res. 2000;53:600-4.

52. Hazer DB, Sakar M, Dere Y, Altinkanat G, Ziyal MI, Hazer B. Antimicrobial effect of polymer-based silver nanoparticle coated pedicle screws: Experimental research on biofilm inhibition in rabbits. Spine (Phila Pa 1976). 2016;41:323-9. 